\title{
Arteterapia y migración: inclusión social a través de la apropiación simbólica del paisaje
}

Recibido: 09/03/14

\author{
Mónica MuÑOz MONTEJANO ${ }^{1}$ \\ monica3mnk@gmail.com \\ $M^{\text {a Teresa CRESPO SIERRA }}{ }^{2}$ \\ Universidad de Valladolid \\ crespomt@psi.uva.es
}

Aceptado: 23/10/14

\section{RESUMEN}

Este artículo parte de una revisión bibliográfica sobre el tema del paisaje y su influencia en el individuo de forma tanto individual como grupal, personal y cultural. Se analiza el estado de la cuestión desde las perspectivas psicológica, social, cultural, geográfica y artística para realizar, a partir de ello, aportaciones interdisciplinares, especialmente dirigidas a colectivos de personas migrantes, que puedan abordarse a través del arteterapia. De este modo se pretende elaborar y reelaborar la práctica arteterapéutica con población migrante desde nuevas perspectivas que incluyan el estudio del paisaje y su influjo en el desarrollo individual y social.

Palabras clave: Paisaje, apropiación, arteterapia, migración, identidad.

\section{Referencia normalizada}

MUÑOZ MONTEJANO, M., CRESPO SIERRA M.T. (2014). “Arteterapia y migración: inclusión social a través de la apropiación simbólica del paisaje". En Arteterapia: Papeles de arteterapia y educación artística para la inclusión social Vol.: 9. Páginas 13-24. Madrid.

\section{SUMARIO}

Introducción; Paisaje, cultura e identidad; Percepción, representación y paisaje en el arte contemporáneo; La intervención con arteterapia; Conclusiones.

\section{Art therapy and migration: social inclusion throug landscape symbolic appropriation}

\begin{abstract}
This work is essentially a literature review about landscapes and its influence on people. We analyze the state of affairs from psychological, social, cultural, geographic and artistic perspectives, to do interdisciplinary contributions that could be adressed through art therapy, at migrants groups. In this way, we are trying to develop and remake art therapy practice with migrant groups by new

\footnotetext{
${ }^{1}$ Licenciada en Bellas Artes (Universidad Miguel Hernández) y Arteterapeuta, Máster en Arteterapia y Educación Artística para la Inclusión Social (Universidad de Valladolid). Impulsora y codirectora de Sublimarte. Revista Digital de Terapias Creativas.

${ }^{2}$ Profesora de Psicología: Departamento de Psicología en la Facultad de Educción y Trabajo social. Universidad de Valladolid.
} 
points of view interested in the landscape study and its influence on individual and social development.

Key words: Landscape, appropriation, art therapy, migration, identity.

\section{CONTENTS}

Introduction; Landscape, culture and identity; Perception, representation and landscape in contemporary art; The intervention with art therapy; Conclusions.

\section{Introducción}

Nuestra inquietud por abordar y trabajar la intervención y transformación del paisaje a través del arte, como medio para mejorar la inclusión social de personas migrantes, surge tras la realización de un taller de arteterapia llevado a cabo en un centro de migraciones de Madrid, en la medida en que el desarraigo, la desorientación y ansiedad, debidos al impacto social y cultural al que se tienen que enfrentar, son algunas de las características principales y comunes del colectivo. Por ello, tras un primer contacto con la metodología del trabajo del centro, y teniendo muy en cuenta los recursos y posibilidad de acceso a algunos de los usuarios del mismo, se propone trabajar la autoestima y la identidad tanto personal como cultural desde un enfoque contextual. En concreto, la intervención se aborda incidiendo en la experiencia y vivencia del paisaje, a partir de la cual generar contenido simbólico para posibilitar la apropiación del entorno a través de la creación artística.

Los objetivos propuestos en esta intervención sobre inclusión social de la población migrante pueden verse facilitados mediante la apropiación simbólica del paisaje, donde el arteterapia se utiliza como una herramienta mediadora en dicho proceso lo que nos conduce, por un lado, a conocer de qué forma influye el paisaje en el ser humano desde una perspectiva social, cultural y artística y por otro, a plantear las aportaciones que pueden hacerse desde el arteterapia, como método de trabajo para mejorar la inclusión social, especialmente en el colectivo de personas migrantes más vulnerables.

\section{Paisaje, cultura e identidad}

Todos los escenarios en los que el individuo desarrolla su vida diaria desempeñan un importante papel en la configuración de su identidad así como en el sentimiento de pertenencia a un grupo. Se considera el paisaje como un reflejo de la relación del individuo con su entorno, lo cual tiene una gran relevancia en el proceso vital de cada persona. Ante la situación de desarraigo familiar, social y cultural a la que se ven sometidas las personas que se han visto forzadas a abandonar su país, se propone el trabajo simbólico con el paisaje como elemento para la inclusión y la mejora psicosocial de estos colectivos. De esta forma, participar en el paisaje, es decir, interpretarlo y transformarlo por medio de la actividad artística, permitirá al creador apropiarse de forma simbólica del mismo, formar parte de él y encontrar su propio lugar dentro del nuevo contexto. En este sentido se plantea la idea de paisaje como elemento formal que lleva implícita una carga 
social, cultural y geográfica que permanece como parte inseparable de cada individuo.

Enmarcados en el contexto artístico utilizaremos la denominación paisaje para referirnos a todo tipo de espacios que, como tales, conllevan una carga social, cultural, geográfica y estética porque el paisaje es aquello que permite interpretar en términos culturales y estéticos las cualidades de un territorio. El entorno y el espacio son considerados paisaje al ser experimentados desde perspectivas multidisciplinares como la arquitectura, el arte, la geografía, la psicología o la filosofía. El término no supone exclusivamente un espacio abierto al aire libre, sino que entendemos como paisaje todo espacio que rodea al individuo, todo ambiente en el que se desenvuelve y que percibe a través de sus sentidos, lo cual incluye espacios abiertos, cerrados, amplios, pequeños, naturales, construidos, rurales, urbanos, agradables, desagradables, confortables, incómodos, etc. En definitiva, utilizamos el término paisaje como un concepto, en lugar de como una temática o disciplina cerrada.

Para profundizar en la relación individuo-paisaje, es imprescindible considerar la función de la mirada en este proceso, en la medida en que ésta forma el paisaje, concreta el territorio y modela las formas que vemos de nuestro entorno. Esto será diferente en cada individuo, debido a la percepción y experiencia que cada uno tenga de su propio entorno. El paisaje queda definido por multitud de factores y de ellos, toma prioridad el concepto de representación cultural, entendido como la imagen que elabora el individuo a partir de la percepción de la realidad y condicionada por ciertos rasgos culturales. Es en este origen donde se plantea la paradoja de la cultura, la cual condiciona al paisaje y a su vez, ésta es condicionada por el paisaje. Todo paisaje es cultural porque, además de ser percibido por cada persona bajo unos parámetros culturales concretos, responde al reflejo de las prácticas económicas, sociales, políticas y religiosas que se llevan a cabo en él.

Por su parte, Claval (1999) afirma que las culturas se forman a partir del resultado de un trabajo de construcción que desarrollan en relación al espacio, la naturaleza, la sociedad, los medios y las maneras de explotarlos. Del mismo modo crean su cultura, en función a lo que puedan extraer de lo que tienen a su alcance, sacan partido de la naturaleza para alimentarse, ampararse de la naturaleza, vestirse, alojarse, etc., y modelan el espacio a su imagen; todo ello en función de sus valores y de sus aspiraciones.

En una época en que la cultura se aborda en términos de comunicación, el paisaje retiene la atención porque sirve de soporte a las representaciones. El paisaje es a la vez matriz e impronta de la cultura. Matriz puesto que las instalaciones y las formas que lo estructuran contribuyen a transmitir usos y significados de una generación a otra; impronta, porque cada grupo contribuye a modificar el espacio que utiliza y a grabar las marcas de su actividad en él - esto es lo que estudiaba la geografía de principios de siglo - y los símbolos de su identidad. (Claval, 1999:34). 
No es extraño que las diferentes culturas se hayan ido formando a lo largo de la historia vinculadas al espacio y al lugar en el que se desarrollaban, donde el paisaje se construye y es una creación humana en la que el componente cultural queda estrechamente unido a él. En cada época y en cada sociedad se han elaborado imágenes del mundo y del entorno que responden a las creencias, conocimientos y deseos que poseían. El ser humano ha construido, por tanto, la cultura en relación al paisaje y el paisaje en relación a la cultura, creciendo ambos simultáneamente y alimentándose para construirse y transformarse recíprocamente.

Las diferentes culturas se conforman en relación directa con el ambiente, definiéndose a lo largo de la historia y determinadas, en gran medida, por las circunstancias naturales en las que se encontraban inscritas, las cuales condicionaban y guiaban la forma de vida, los rituales, las creencias $\mathrm{y}$, por tanto, la tradición. A través de mitos y leyendas las culturas se mantienen, persisten y evolucionan. Los mitos tienen un fuerte componente simbólico que reside en lo más profundo de la mente humana, conectando con imágenes arquetípicas, heredadas genéticamente. Siguiendo a Jung, el alma contiene todas las imágenes de las que han surgido los mitos y estos se componen de un gran número de elementos arquetípicos que han sido transmitidos por la tradición, por lo que, aunque hayan surgido de contenidos propios del inconsciente colectivo, se han transformado en material consciente, inevitablemente cargados de contenido cultural.

El paisaje recoge por tanto las huellas de un pasado, pero a su vez, encontramos en él la realidad más inmediata y los indicios de lo que está por llegar. En el paisaje se inscribe la historia y contiene leyendas y mitos a través de los que desenvolverse, vivir, crecer, aprender e interpretar la naturaleza y el entorno en el que cada individuo desarrolla su proceso vital.

Para comprender el papel que desempeña el espacio que nos rodea para la formación y definición de la identidad, Valera y Pol (1994) destacan que las primeras preguntas que se hacen a alguien que acabamos de conocer para saber algo más acerca de quién es esa persona, muy probablemente son: ¿De dónde eres? o ¿Dónde vives? La respuesta a estas preguntas sitúa a la persona dentro de un marco de referencia, de un espacio y un lugar con unas características concretas que serán parte fundamental en la configuración de su identidad social. A partir de estas reflexiones, entendemos la presencia que tiene el contexto en el que vivimos y el papel fundamental que desempeña en la formación de nuestra identidad. De este modo, el nivel al que se encuentran los lugares y espacios de la vida cotidiana en relación a la formación de la identidad, son equiparables al de los individuos con los que la persona se relaciona, así como la importancia de los elementos simbólicos como elementos que ayudan a configurar una identidad social determinada. La identidad de lugar consiste en el conocimiento de aquellos lugares o espacios donde la persona desarrolla su vida cotidiana y, en función de los cuales, el individuo puede establecer vínculos emocionales y/o de pertenencia a determinados entornos. Estos vínculos son tan importantes como los que se establecen con los diferentes grupos sociales con los que el individuo se relaciona. 
Además de las prácticas sociales aparecen, como elementos influyentes en la formación de la identidad social, algunos espacios que resultan especialmente significativos para los miembros del grupo y, cuyo papel en el sentimiento de pertenencia al mismo, resulta de gran relevancia porque, como afirman Vidal Moranta y Pol Urrútia (2005), en la relación identidad-entorno existen tres procesos que, de manera dialéctica, provocan la continuidad y el cambio en la identidad: identificar el entorno, ser identificado por el entorno e identificarse con el entorno. Todos estos factores se ven alterados durante el proceso migratorio y pueden suponer un conflicto en el proceso de configuración de la identidad de la persona migrante debido a una falta de conexión entre el nuevo contexto y su ambiente anterior.

El nuevo contexto en el que la persona migrante debe desenvolverse, va a influir directamente en su identidad individual, ya que cada persona ha desarrollado su propia identidad en relación a un entorno que después ha cambiado. Por ello, este aspecto es uno de los que más sufren durante el proceso migratorio porque, además de una serie de rasgos físicos, es un conjunto de símbolos y valores imprescindibles para abordar la realidad cotidiana. Debido a que la persona migrante integra en su identidad la condición de "inmigrante" así como adquiere aprendizajes en su recorrido, su identidad permanece en continua transformación. A todo esto, debemos sumar la realidad social en que la mayoría de las personas migrantes se encuentran cuando llegan al país de acogida. Debido a su poder adquisitivo, suelen centrar su residencia en barrios de bajo nivel socio-económico, por lo que esta concentración, asociada a necesidades económicas y sociales, se convierte en un elemento estigmatizante más.

En nuestro caso de estudio, las personas migrantes se ven abocadas a residir en lugares que dificultan su inclusión, ya que marcan un importante sesgo entre la población. Todo ello contribuye a un mayor riesgo de exclusión social así como a mayor vulnerabilidad de este grupo de población.

\section{Percepción, representación y paisaje en el arte contemporáneo}

De todos los sentidos, el más vinculado a la percepción ha sido siempre la visión. Independientemente de que éste no sea el único que interviene en dicho proceso, es considerado por numerosos autores como el de mayor importancia y a través del cual se registra la mayor cantidad de información que será accesible a la mente. Es importante reconocer que estas teorías están orientadas a sujetos que tienen intactas las capacidades sensoriales visuales, lo cual sería absolutamente diferente en individuos que tuvieran algún tipo de alteración en este sentido. En ese caso, el principal canal de recepción no sería el visual, sino que pasarían a tomar protagonismo otros como el auditivo o el táctil, los cuales están siempre presentes pero quedan, generalmente, supeditados a la visión. De cualquier modo, la percepción final estará configurada por todos los sentidos a través de los cuales seamos capaces de registrar. En ocasiones, esto puede realizarse de forma inconsciente, sin darnos cuenta de los olores o los sonidos y, sin embargo, ésta será información muy relevante en la configuración final del entorno percibido. 
Incidimos en la subjetividad de la percepción del paisaje porque cada persona registramos la realidad de distinta forma. En función del canal receptor principal el sujeto observará lo que le rodea de un modo u otro, del mismo modo que, dependiendo de los significados que atribuyamos, lo observado por cada individuo será diferente. Esto será fundamental en el momento de la representación. El diálogo entre lo observado-sentido y su significado, dará lugar a la representación del paisaje percibido.

La vinculación del paisaje con la cultura construye, en el proceso perceptivo, una imagen elaborada a partir de la proyección de contenidos, valores y significados culturales que derivan en el término paisaje como representación cultural. El individuo reconoce en el lugar una serie de connotaciones económicas, políticas, religiosas, etc. que van a funcionar como condicionantes en la percepción individual. Para Nogué (2010) el paisaje es, a la vez, una realidad física y la representación que culturalmente nos hacemos de ella; la fisonomía externa y visible de una determinada porción de la superficie terrestre y la percepción individual y social que genera; un tangible geográfico y su interpretación intangible. Es, a la vez, el significante y el significado, el continente y el contenido, la realidad y la ficción.

Tomando la experiencia como elemento fundamental en nuestro estudio, debemos incidir en la relación que se establece entre lo experiencial y la percepción, condicionándose ambas mutuamente. Debido a que la percepción del paisaje no implica exclusivamente el registro de la realidad por medio de los sentidos sino que, además, se le atribuye un significado, al representar el paisaje se ponen en juego tanto los elementos formales como aquellos conceptuales que hacen referencia a los significados subjetivos que cada individuo aporta a lo percibido. Siendo así, podemos afirmar que los significados subjetivos de cada persona forman parte de elaboraciones relacionadas con sus experiencias previas. De este modo la propia subjetividad se pone de relieve en el momento de la representación, haciéndose explícito el significado último que cada persona otorga en el proceso de percepción.

En el acto de proyectar las imágenes mentales personales, el individuo se adentra en el proceso de la creación. No solo captura el paisaje a través de los sentidos, sino que lo identifica con el propio cuerpo, con la experiencia vital, interiorizando las percepciones y proyectando sus imágenes mentales sobre él.

Para hablar de la experiencia artística del paisaje, nos proponemos hacerlo desde propuestas artísticas contemporáneas, en las que la creación no es algo pasivo, contemplativo o externo al creador, sino en aquellas en las que éste toma el protagonismo desde una conciencia del entorno en la que se implica corporal y mentalmente. Porque el hecho de recorrer activamente un espacio proporciona una perspectiva perceptiva distinta a la de aquel que simplemente se posiciona ante él para contemplarlo en la distancia. Supone una comprensión e interpretación del paisaje que surge de la implicación directa del individuo en el mismo. 
Cada vez más, se entiende la experiencia del paisaje desde el mismo acto de caminar. El recorrido se convierte en la mejor forma de conocer y percibir un paisaje que, lejos de adquirir un único punto de vista, dialoga entre el espacio, el tiempo y la persona. Porque caminar no sólo permite al individuo una relación directa con el paisaje, supone un intercambio vital, permite un conocimiento específico y subjetivo de la realidad, una experimentación del espacio basada en el encuentro y en el reconocimiento tanto de lo que le rodea como de sí mismo.

En la exposición Cartografías Contemporáneas. Dibujando el pensamiento, (Dossier de prensa ${ }^{3}$, 2013), encontramos referencias al cuerpo como medida para conocer y relacionarnos con el mundo. Éste es nuestra referencia, con él percibimos y acotamos el espacio a nuestro alrededor. Medimos en pies o en palmos y hablamos de cuerpos celestes o de las arterias de la ciudad. En un momento en el que la experiencia es la protagonista de la percepción y tomando el propio cuerpo como referente, como medio e instrumento a través del cual relacionarnos con el entorno, se potencia todavía más la subjetividad. En el cuerpo tenemos localizados los sentidos, pero en función de la relación de cada individuo con su propio cuerpo, la experiencia sensorial será diferente.

La experiencia es por tanto algo fundamental en la relación con el entorno y en la percepción del paisaje. En el arte contemporáneo se toma como parte indispensable del proceso creativo, utilizando el cuerpo como referente a partir del cual interpretar lo que nos rodea. En numerosos casos, la misma experiencia de caminar es suficiente para reconocer esa relación del individuo con el entorno así como la existente entre él y su propia existencia.

Resulta incuestionable que el paisaje se ha trabajado de múltiples formas a lo largo de toda la historia del arte. Sin embargo, los primeros movimientos artísticos que tomaron el paisaje de forma experiencial, vinculándolo a la identidad y el descubrimiento personal fueron los dadaístas a quienes siguieron los surrealistas. Éstos últimos, interesados por el psicoanálisis y la obra de Sigmund Freud, pusieron en práctica estrategias creativas a partir de acciones en las que se proponían caminar o deambular sin rumbo ni destino prefijado, investigando acerca de la percepción estética del entorno. En sus acciones integraban lo racional con el mundo de los sueños, lo consciente y lo inconsciente, afirmando que de esta acción surgían comportamientos primitivos e incidiendo en la subjetividad individual de la percepción del paisaje. A partir de las ideas surgirían más tarde las inquietudes situacionistas, quienes las derivaron en lo que denominaron mapas psicogeográficos.

En nuestra propuesta concreta por facilitar la inclusión social de la población migrante, centramos la atención en artistas contemporáneos cuya visión y representación del paisaje mantiene una relación directa con la experiencia personal y

\footnotetext{
${ }^{3}$ Caixafórum (2013). Exposición Cartografias Contemporáneas. Dibujando el pensamiento. Dossier de prensa. Madrid: Obra Social La Caixa.
} 
el proceso vital, aportando al paisaje cualidades de temporalidad, mutación e indeterminación. El arte contemporáneo alberga conceptos como el happening, performance, body art, land art... Éstas, más que disciplinas artísticas, podríamos denominarlas arte interdisciplinar, en el que la obra es una acción, un suceso, algo efímero, donde lo que cobra valor es la experiencia, el hecho y la participación; es decir, un tipo de manifestación artística ligada a los intereses personales e individuales pero también de significación colectiva, relacionados con inquietudes emocionales, sociales y culturales.

Son numerosos los referentes que, en la historia más reciente, han hecho su aportación a la investigación artística en el paisaje. En concreto, los "situacionistas", proponen una experiencia lúdica del paisaje y de la ciudad y elaboran la teoría de la deriva y la psicogeografía como forma de cartografiar las emociones y las relaciones existentes entre el individuo y el entorno urbano. A finales de la década de los 60 , surgen muchos artistas que retoman estos conceptos y desarrollan su obra a partir de ellos, buscando una reflexión entre el artista y su entorno. Richard Long, apuesta por la experiencia de caminar como acción artística, en vez de por el objeto. Sus producciones se realizan con elementos naturales y la temática aborda los recorridos, trayectos y experiencias surgidas del acto de andar y su interacción con la naturaleza. Otros artistas, como Alberto Carneiro o Bruce Nauman, no se basan únicamente en la experiencia pero consideran que la obra de arte debe surgir de la experimentación. Carneiro, explora el territorio de forma exhaustiva y a partir de sus sensaciones hacia el espacio y la naturaleza, produce sus esculturas. El cuerpo ocupa un papel fundamental en su obra de igual forma que se hace indispensable en el trabajo de Nauman. Gran parte de su trabajo se desarrolla a partir de los conceptos espacio y tiempo. En definitiva, experimenta, explora, investiga los lugares en relación al tiempo y a su propio cuerpo, sirviéndose de recursos audiovisuales como soporte y registro de sus acciones.

Se puede considerar a estos artistas como precursores de iniciativas relacionadas con la experiencia del espacio pero hubo muchos otros que, a partir de las investigaciones artísticas de esta época, trataron de explorar las posibilidades que plantea el paisaje en relación al individuo y al propio cuerpo. Destacan Walter de María (1968) con su obra One Mile Long Drawing, Robert Smithson (1967) con Monuments of Passaic, Dennis Oppenheim (1969) con Shoes prints, o Christo y Jeanne Claude (1978) con Wrapped Walk Way.

A partir de estas experiencias y el impulso que estos artistas aportaron al trabajo con el paisaje, se precipitaron los movimientos de "land art" y "earth work", y surgieron nuevas propuestas relacionadas con estos conceptos que se siguen desarrollando e investigando en el panorama artístico contemporáneo. Uno de los colectivos actuales que toma directamente la experiencia de caminar como práctica estética es Stalker que centra su actividad en investigaciones urbanas, como forma de transformación del espacio y construcción del paisaje. El colectivo, que se compone de un número variable de miembros, "propone estrategias experimentales de intervención basadas en prácticas de exploración espacial, usando 
técnicas interactivas y lúdicas que se relacionan con un entorno, sus habitantes y su cultura local" (http://www.osservatorionomade.net/). Por medio de estas técnicas investigan y participan junto a la población local de las transformaciones del espacio. Por su parte, Careri (2002) propone el acto de caminar como experiencia estética partiendo de reflexiones que abarcan desde el nomadismo hasta el movimiento de "land art", tomando la experiencia de caminar como principio de la obra de arte y de la construcción simbólica del espacio, desde la elevación de los menhires hasta el momento actual.

\section{La intervención con arteterapia}

El paisaje, reconocido como una representación estrechamente vinculada a la cultura, la identidad y lo simbólico, se propone como medio de trabajo para intervenciones con arteterapia dirigidas a colectivos de personas migrantes. Se pretende proporcionar una vía de trabajo que favorezca su inclusión social a partir de establecer vínculos con el nuevo entorno para ayudar a configurarlo como un espacio significativo.

Por ello la intervención se apoyará en el trabajo simbólico con el paisaje como recurso para re-elaborar la propia identidad en relación a un lugar a través de la percepción individual y el trabajo artístico personal. Participar en el paisaje, es decir, interpretarlo y transformarlo por medio de la actividad artística, permitirá al creador apropiarse de él de forma simbólica.

Desde la psicología social y ambiental se defiende la apropiación del espacio como forma de favorecer los vínculos entre las personas y los espacios, entendidos como construcción social de lugares, de donde se destacan el espacio simbólico, la identidad y el apego al lugar como principales conceptos en la medida que la apropiación permite a la persona hacerse a sí misma mediante las propias acciones, en un contexto sociocultural e histórico puesto que, la apropiación se resume en dos procesos principales: la acción-transformación, mediante la cual la persona deja su huella simbólicamente en el entorno a través de señales y marcas; y la identificación simbólica, vinculada a los procesos afectivos, cognitivos e interactivos. (Vidal y Pol, 2005:283).

$\mathrm{Si}$ consideramos que una de las categorizaciones que configura la identidad social de un individuo o de un grupo es la que se deriva del sentido de pertenencia a un entorno, parece correcto pensar que los mecanismos de apropiación del espacio aparecen como fundamentales para este proceso de identificación. Sea a través de la acción-transformación o bien de la identificación simbólica el espacio se convierte en lugar, es decir, se vuelve significativo. El mecanismo de apropiación facilita el diálogo entre los individuos y su entorno en una relación dinámica de interacción, ya que se fundamenta en un doble proceso: el individuo se apropia del espacio transformándolo física o simbólicamente y, al mismo tiempo, incorpora a su self determinadas cogniciones, afectos, sentimientos o actitudes relacionadas con el espacio que resultan parte fundamental de su propia definición como individuo, de su identidad del self. (Valera y Pol, 1994:13). 
A partir de ello construímos el marco teórico bajo el cual se encuadra la intervención, definido por la creación artística como forma simbólica de apropiación del paisaje.

Tras la revisión teórica realizada y basándonos en las posibilidades de la arteterapia en el trabajo con población migrante, formulamos los siguientes objetivos para una propuesta de intervención:

- Crear y fortalecer los vínculos con el nuevo entorno.

- Proporcionar herramientas y habilidades a los participantes para desarrollar capacidades que permitan la re-significación del entorno en relación a su identidad individual y social.

- Favorecer capacidades relacionadas con la resiliencia y la tolerancia a la frustración.

- Proporcionar un espacio de seguridad en el que, a través de la producción plástica, se favorezca el empoderamiento de la persona.

Metodológicamente, se plantea la práctica artística desde una perspectiva vivencial; es decir, desde propuestas artísticas en las que el creador toma el protagonismo a partir de una conciencia del entorno en la que se implica corporal y mentalmente. Se basa en un enfoque triangular, estableciendo relaciones entre el paisaje, la cultura y la identidad. Y en relación a los contenidos se propone un trabajo a partir de técnicas como la fotografía y el vídeo principalmente, aunque se pueden complementar con otras como pintura, collage, dibujo, etc. El carácter interdisciplinar del proyecto hace posible la interacción de diferentes técnicas, a través de las cuales permitir una exploración del entorno y elaborar un trabajo artístico. A partir de la exploración y reconocimiento de los espacios próximos al centro donde se desarrolla el taller de arteterapia así como a los espacios habituales de cada uno de los participantes, elaborarán sus producciones artísticas personales bajo el acompañamiento y la orientación de la arteterapeuta.

\section{Conclusiones}

Tras conocer y comprender cómo el paisaje determina al ser humano y el ser humano al el paisaje, especialmente en cuestiones culturales y de identidad individual y social, se considera que el arteterapia es una vía eficaz para ayudar a establecer vínculos con el nuevo lugar y así contribuir a la mejora psicosocial de la población migrante.

Siendo este colectivo extremadamente heterogéneo, tanto por sus circunstancias personales como por su procedencia, edad, género, nivel cultural, etc., resulta especialmente difícil una intervención grupal que atienda a las necesidades concretas. Sin embargo, a través de la intervención en el paisaje, se posibilita la expresión y comunicación por medio de técnicas y materiales plásticos accesibles a todas las personas independientemente de las características particulares. Al realizar las propuestas a partir de la experiencia individual del paisaje, se da la posibilidad a la persona de trabajar, no sólo los aspectos comunes al resto del grupo, sino también los subjetivos, utilizando el contenido emocional propio. A través de la intervención y la interacción en el paisaje, se da lugar a la participa- 
ción en el nuevo contexto, generando espacios de inclusión que permitirán a la persona vincularse con el entorno, sintiendo que forma parte del lugar e identificándose con el mismo.

Para llevar a cabo todo lo anterior, resulta imprescindible ser consciente de las posibilidades personales, aceptar la situación individual de la persona, permitirá valorar los inconvenientes así como descubrir las potencialidades. Desarrollar la capacidad de resiliencia será fundamental para conseguir llevar a cabo este propósito. De esta forma, el sujeto resiliente será capaz de construir un proyecto vital a pesar de las posibles circunstancias adversas. Todo proyecto vital es necesario hacerlo en relación a un contexto, es por ello que las propuestas de intervención deben ajustarse a la interpretación del paisaje como forma de relacionarse con el medio en el que cada individuo va a desarrollar su proyecto de vida. La creación artística permite trabajar desde lo simbólico y lo metafórico, a partir de lo cual la persona interpreta, transforma, cambia y se apropia del paisaje. Después de este proceso, el paisaje ya no se presenta extraño, ya no es un lugar ajeno, sino que la persona puede encontrarse en él, conectarlo con sus intereses y descubrirlo como un lugar que le pertenece. El paisaje ajeno y colectivo se convierte en un paisaje compartido, personal y subjetivo. El trabajo creativo implica una unión, una construcción en la que la persona inscribe su subjetividad a través de la percepción, la experiencia y la representación.

Desde el punto de vista metodológico, la forma de trabajo incluye la experiencia ambiental. De esta manera, las sesiones no se desarrollan exclusivamente dentro de una sala, el espacio seguro y de confianza que debe proporcionar una sesión de arteterapia. Sin embargo, al tratarse de una intervención enfocada a la inclusión social, se considera fundamental llevar a cabo las sesiones no sólo en el espacio del taller, sino también en el contexto real, participando activamente e involucrando todos los sentidos para que el individuo consiga llevar a cabo el proceso de encuentro e identificación con el paisaje.

En este aspecto, con este trabajo se abren líneas de investigación en arteterapia no solo hacia una metodología sino hacia un espacio y un lugar. Hacia el desarrollo de las sesiones de arteterapia en base a la creación a partir de la experimentación con el paisaje, los recorridos, en los espacios que habitamos, que transitamos, que conocemos y desconocemos. A través del paisaje, pueden trabajarse conceptos relacionados con el bienestar psicosocial que devengan en un crecimiento personal y una mejora de la calidad de vida. La apropiación simbólica del espacio que nos rodea puede ser un medio a través del cual establecer una relación de uno mismo con su entorno, hallando puntos de encuentro y diferencias que ayuden al individuo a conocerse mejor, a valorar todos los aspectos relacionados con su identidad y a generar vínculos que le permitan desarrollarse completamente y de forma saludable en su paisaje. 


\section{Referencias bibliográficas}

CARERI, F. (2002). Walkscapes. El andar como práctica estética / Walking as an aesthetic practice. Barcelona: Gustavo Gili.

CLAVAL, P. (1999). Los fundamentos actuales de la geografía cultural. Documents d'Anàlisi Geogràfica, 34, 25-40.

NOGUÉ, J. (2010). Paisaje y comunicación: el resurgir de las geografías emocionales. En T. Luna y I. Valverde (Eds.) Teoría y paisaje: reflexiones desde miradas interdisciplinares (pp 25-42). Barcelona: Observatorio del Paisaje de Cataluña y Universidad Pompeu Fabra.

VALERA, S. Y POL, E. (1994). El concepto de identidad social urbana: una aproximación entre la Psicología Social y la Psicología Ambiental. Anuario de Psicología, 62, 5-24.

VIDAL MORANTA, T. Y POL URRÚTIA, E. (2005). La apropiación del espacio: una propuesta teórica para comprender la vinculación entre las personas y los lugares. Anuario de Psicología, 36, 281-297 